\title{
ANALISIS MODEL SIMULASI BERBASIS ALGORITMA DALAM PENINGKATAN KOMPETENSI MANAJEMEN KESIAGAAN BENCANA PERAWAT KOMUNITAS KOTA SURAKARTA
}

\author{
Addi Mardi Harnanto ${ }^{* 1}$, Sunarto ${ }^{2}$ \\ Poltekkes Kemenkes Surakarta Jurusan Keperawatan
}

\begin{abstract}
Background: The Republic of Indonesia is a country that is vulnerable to disasters. Disaster preparedness is an important component in disaster management in order to reduce mortality or morbidity. One component of the community component that plays a role in disaster preparedness is health workers including nurses. The role and competence of disaster management must be considered and enhanced for community nurses to ensure the safety of the community in dealing with disasters starting from the prevention phase, the mitigation phase, the preparedness phase, the emergency response phase and the recovery phase. Algorhythms is an effective method in increasing understanding in a training or simulation.This study was conducted to analyze the effectiveness of the algorithm based algorithm can increase competency of disaster preparedness management in community nurses in the city of Surakarta. Methods: This type of research is a comparative experimental study with a pretest-post test with control group design. The population in this study were all community nurses in the city of Surakarta as many as 110 people. The sampling technique was a total sampling of 97 people (88\%). Data is tested by Difference Test. Results: There was an increase in the value of roles and competencies in all groups. Difference in value improvement in the treatment group is (role $=2.56$ and competence $=2.76$ ). While the increase in value in the control group is (role $=2.05$ and competence $=1.88$ ). Value of $P=0.00$. Conclusion: There are significant differences in the value of roles and competencies between the treatment and control groups. Increasing the value of the role and competence of the simulation group with algorithm learning is higher than the control group.
\end{abstract}

Keywords: Simulation, Algorithm, Disaster Preparedness, Community Nurse

\section{PENDAHULUAN}

Negara Kesatuan Republik dunia yaitu Lempeng Indo-Australia, Indonesia adalah negara yang memiliki Eurasia, dan Pasifik. Ring of fire dan kerentanan terhadap bencana baik bencana berada di pertemuan tiga lempeng alam maupun bencana yang disebabkan tektonik menempatkan negara kepulauan karena faktor kelalaian manusia.. ini berpotensi terhadap ancaman bencana Masyarakat Indonesia perlu menyadari alam. Terdapat resiko bencana alam dan bahwa wilayah nusantara ini memiliki 129 bencana sosial di Kota Surakarta. gunung api aktif, atau dikenal dengan ring Tercatat pernah mengalami beberapa kali of fire, serta terletak berada pada peristiwa banjir pada Bulan Maret 1966, pertemuan tiga lempeng tektonik aktif Maret 1968, Maret 1973, Februari 1974, 
Maret 1975, Januari 1982, Desember 2007, Februari 2009 (Prasetya dalam Istiqomah, 2014). Secara geomorfologisnya, Kota Surakarta merupakan kawasan rentan banjir karena berada di zone depresi (intermontain plain) yang diapit Gunung Api Lawu, Gunung Api Merapi dan Pegunungan Seribu. Kota Surakarta mayoritas berelief datar, namun memiliki banyak cekungan terutama di Kota Surakarta bagian timur dan sekitar anak sungai yang melewati Kota Surakarta. Cekungan-cekungan tersebut berpotensi menimbulkan genangan. Kawasan dari Sudiroprajan ke arah Timur hingga Kampung Sewu dulunya adalah rawa-rawa yang berarti dari dulu Kota Surakarta sebelah Timur memang daerah sasaran banjir. Air permukaan yang masuk Kota Surakarta berasal dari tiga arah yaitu dari lereng Tenggara Gunung Api Merapi, lereng Barat Gunung Api Lawu dan Wonogiri dengan 9 anak sungai yang masuk ke Bengawan Solo. Bentuk DAS Solo Hulu yang luas dan melebar, bahkan mendekati pola radial mengakibatkan waktu kosentrasi air di Bengawan Solo seragam ketika terjadi hujan. Diperparah dengan hulu Bengawan Solo di Wonogiri adalah Karst/tanah gersang berbatu yang koefisien aliran permukaannya tinggi (Istiqomah, 2014).

Berdasarkan dari uraian latar belakang di atas, dipandang perlu untuk melakukan penelitian tentang "Analisis Model Simulasi Berbasis Algoritma Dalam Peningkatan Peran dan Kompetensi Manajemen Kesiagaan Bencana Pada Perawat Komunitas di Kota Surakarta."

\section{METODE PENELITIAN}

Penelitian ini menggunakan adalah rancangan penelitian comparatif experimental study dengan desain pretestpost tes with control group. Pendekatan penelitian ini menggunakan cross sectional. Penelitian ini telah dilaksanakan di Kota Surakarta pada bulan Maret sampai dengan September 2019. Populasi pada penelitian ini yaitu Dari 110 calon responden yang diundang dalam pengambilan data, hadir 100 orang perawat dan $94(85,4 \%)$ data dinyatakan layak dan memenuhi untuk dianalisis dan Uji statistik yang digunakan adalah uji t.

\section{HASIL PENELITIAN}

Penelitian dilaksanakan di kota Surakarta dengan 110 calon responden yang diundang dalam pengambilan data, hadir 100 orang perawat dan 94 (85\%) data dinyatakan layak dan memenuhi untuk dianalisis dengan 94 responden, responden laki-laki yaitu 28 dan perempuan 66. Dari 94 responden, mayoritas berumur antara 31-40 tahun yaitu 35 orang $(37,2 \%)$. Responden dengan usia antara 20-30 tahun adalah sebesar 12 orag (12,8\%), Responden dengan usia 41-50 tahun adalah sejumlah 28 orang $(29,8 \%)$. Sedangkan responden dengan usia di atas 50 tahun adalah sejumlah 19 orang $(20,2 \%)$ responden, mayoritas berpendidikan DIII Keperawatan yaitu 39 orang $(41,5 \%)$. Responden dengan pendidikan SPK adalah sejumlah 3 orag $(3,2 \%)$, Responden dengan pendidikan DIV/S1 Keperawatan adalah sejumlah 30 orang $(31,9 \%)$. Responden dengan pendidikan Ners adalah sejumlah 20 orang $(21,3 \%)$. Sedangkan responden dengan pendidikan S2 sejumlah 2 orang (2,1\%). Dari 94 responden, mayoritas responden memiliki 
masa kerja di atas 25 tahun yaitu sejumlah 24 orang $(25,5 \%)$. Responden dengan masa kerja antara 0-5 tahun adalah sejumlah 13 orag $(13,8 \%)$, Responden dengan dengan masa kerja antara 6-10 tahun adalah sejumlah 22 orang $(23,4 \%)$.

Responden dengan masa kerja 11-15 tahun adalah sejumlah 18 orang $(19,1 \%)$. Responden dengan masa kerja 16-20 tahun adalah sejumlah 8 orang $(8,5 \%)$. Responden dengan masa kerja 21-25 tahun adalah sejumlah 9 orang $(9,6 \%)$.
Mayoritas responden memiliki sertifikat pelatihan BTCLS/PPGD yaitu sejumlah 69 orang $(23,4 \%)$. Responden sertifikat pelatihan BLS adalah sejumlah 22 orag $(13,8 \%)$, Responden dengan sertifikat pelatihan ACLS adalah sejumlah 3 orang $(3,2 \%)$. Mayoritas responden belum pernah mengikuti pelatihan kesiagaan bencana yaitu sejumlah 63 orang $(67 \%)$. Sedangkan responden dengan sertifikat pelatihan kesiagaan bencana adalah sejumlah 31 orang $(33 \%)$.

Tabel 1.Distribusi Frekuensi Nilai Rata-rata Peran dan Kompetensi Kelompok Perlakuan

\begin{tabular}{cccccc}
\hline & Peran & \multicolumn{3}{c}{ Kompetensi } \\
\hline Pretest & Postest & Selisih & Pretest & Postest & Selisih \\
\hline 6,25 & 8,81 & 2,56 & 5,44 & 8,2 & 2,76 \\
\hline
\end{tabular}

Sumber : Data Primer (Diolah SPSS for Windows versi 16.00, 2019)

Berdasarkan tabel 1, pada kelompok sejumlah 2,56 dan nilai kompetensi perlakuan, terlihat kenaikan nilai peran sejumlah 2,76

Tabel 2. Distribusi Frekuensi Nilai Rata-rata Peran dan Kompetensi Kelompok Kontrol

\begin{tabular}{cccccc}
\hline & Peran & \multicolumn{3}{c}{ Kompetensi } \\
\hline Pretest & Postest & Selisih & Pretest & Postest & Selisih \\
\hline 6,3 & 8,35 & 2,05 & 5,30 & 7,18 & 1,88 \\
\hline
\end{tabular}

Sumber : Data Primer (Diolah SPSS for Windows versi 16.00, 2019)

Berdasarkan tabel 2, pada kelompok sejumlah 2,05 dan nilai kompetensi kontrol, terlihat kenaikan nilai peran sejumlah 1,88 .

Tabel 3. Hasil Analisis Uji Beda

\begin{tabular}{lc}
\hline Variabel & Nilai P \\
\hline Pretest-postest peran kelompok perlakuan & 0,00 \\
Pretest-postest kompetensi kelompok perlakuan & 0,00 \\
Pretest-postest peran kelompok kontrol & 0,00 \\
Pretest-postest kompetensi kelompok kontrol & 0,00 \\
Selisih kenaikan kelompok perlakuan dan kelompok kontrol & 0,00
\end{tabular}

Berdasarkan tabel 3, didapatkan nilai $\mathrm{P}=0,00$ pada semua faktor yang diukur.

\section{PEMBAHASAN}

Hasil pretest menunjukkan nilai peran dan kompetensi menunjukkan hasil di bawah rata-rata standar. Setelah dilakukan program training dan simulasi didapatkan kenaikan nilai yang sangat signifikan. Studi sebelumnya mengidentifikasi berbagai keterampilan dan kemampuan yang diperoleh sukarelawan dari pengalaman mereka 
(Brook, Missingham, Hocking, \& Fifer, 2007; Cook \& Jackson, 2006; Jones, 2005; Thomas, 2001). Hasil penelitian ini menunjukkan bahwa kombinasi aktivitas relawan meningkatkan pengetahuan, keterampilan, nilai dan motivasi untuk meningkatkan kualitas hidup masyarakat, baik melalui proses politik maupun non politik "(Ehrlich, 2000).

Berdasarkan hasil analisis menunjukkan peningkatan yang signinifikan antara pretest dan posttest. Hal ini menunjukkan bahwa kegiatan simulasi yang dilaksanakan sangat efektif menunjukkan hasil yang baik. Metode simulasi merupakan salah satu metode mengajar yang dapat digunakan dalam pembelajaran kelompok. Proses pembelajaran yang menggunakan simulasi cenderung objeknya bukan benda atau kegiatan yang sebenarnya, melainkan kegiatan mengajar yang bersifat purapura. Kegiatan simulasi dapat dilakukan oleh siswa pada kelas tinggi di Sekolah Dasar. Dalam pembelajaran, siswa akan dibina kemampuannya berkaitan dengan keterampilan berinteraksi dan berkomunikasi dalam kelompok. Disamping itu, dalam metode simulasi siswa diajak untuk bermain peran beberapa perilaku yang dianggap sesuai dengan tujuan pembelajaran (Sa'ud, 2005).

Penelitian Tawalbeh, \& Tubaishat (2013) menunjukkan bahwa studi saat ini menambah bukti-bukti yang positif bahwa metode simulasi sangat mempengaruhi pengetahuan dan kepercayaan diri mahasiswa dalam menerapkan pengetahuan Advance Cardiac Life Support (ACLS). Penelitian lain yang menunjukkan hasil yang sama adalah penelitian Alinier, Hunt, \& Gordon, (2004), Feingold, Calaluce, \& Kallen,
(2004), Goldenberg, et al. (2005), Mole \& McLaffery (2004) yang menyatakan bahwa metode simulasi memiliki efek positif dalam peningkatan pengetahuan, kepercayaan diri dan ketrampilan klinik. Selain itu, metode simulasi juga meningkatkan kemampuan berfikir kritis bagi mahasiswa keperawatan dalam pembelajaran Cardio Pulmonary Rescucitation (Ackermann, 2009; Bruce et al., 2009; Kim \& Jang, 2011; Long, 2005). Perawat-perawat handal yang dibekali dengan soft skill kegiatan kesukarelaan (volunteer) juga membawa dampak yang baik terhadap pemnguasaan peran dan kompetensi. Oleh karena itu, kegiatan pembekalan melalui metode simulasi sangat sesuai karena sangat efektif dalam peningkatan pengetahuan, keterampilan, kepercayaan diri dan kemampuan berfikir kritis.

Disamping itu, metode ini dapat digunakan dalam pembelajaran berbasis konstektual, salah satu contoh bahan pembelajaran dapat diangkat dari kehidupan sosial, nilai-nilai sosial maupun permasalahan-permasalahan sosial yang aktual maupun masa lalu untuk masa yang akan datang. Disaster preparadness merupakan suatu aspek kehidupan sosial yang harus dibiasakan kepada masyarakat terutama bagi masyarakat awam khusus termasuk KSR yang harus mengawal masyarakat dalam menghadapi bencana. Permasalahan- permasalahan yang berkaitan dengan nilai-nilai kehidupan sosial maupun membentuk sikap atau perilaku dapat dilakukan melalui pembelajaran ini (Anitah DKK, 2007).

Hasil penelitian mendukung penelitian sebelumnya yang menyatakan bahwa metode simulasi langsung dengan suatu skenario berdampak positif terhadap peningkatan kemampuan utamanya pada 
ranah psikomotor. Suatu kegiatan mengajar kelas besar yang dibingkai dalam metode simulasi bencana alam adalah dapat diterima dan sangat efektif bagi mahasiswa kedokteran untuk mengembangkan keterampilan non-teknis, kerjasama, negosiasi dan komunikasi yang sangat penting untuk tim bekerja. Desain simulasi bisa menjadi nilai tambah di sekolah-sekolah medis di daerah rawan bencana, termasuk dalam negara berkembang dan sebagai intervensi layak untuk belajar keterampilan non-teknis yang diperlukan untuk keselamatan pasien (Christine Jorm, Roberts, Lim, Roper, Skinner, Robertson, Gentilcore and Osomanski, 2016).

Hasil penelitian kim, Park \& Shin (2016) menunjukkan bahwa simulationbased nursing education memiliki efek yang kuat terhadap pendidikan. Efek yang sangat besar terlihat dalam domain psikomotorik. Sebagai tambahan, pengaruh simulation-based nursing education tidak sebanding dengan tingkat kesetiaan. Oleh karena itu, penting menggunakan semua tingkat yang simulasi yang sesuai untuk memenuhi semua tujuan dan hasil pendidikan.

The Institute of Medicine melaporkan 'To Err is Human' bahwa simulasi diidentifikasi sebagai sarana untuk meningkatkan keselamatan di bidang medis, seperti simulasi penerbangan digunakan untuk meningkatkan keselamatan industri penerbangan. Namun, sementara ada bukti bahwa simulasi dapat meningkatkan kinerja tugas, ada sedikit bukti bahwa simulasi sebenarnya meningkatkan output terhadap pasien. Demikian pula, simulasi saat ini digunakan untuk model kerja sama tim-komunikasi keterampilan untuk manajemen bencana dan peristiwa penting, tetapi sedikit penelitian atau bukti yang menunjukkan simulasi yang meningkatkan respon bencana atau memfasilitasi intersystem atau antar komunikasi. Simulasi berkisar antara penggunaan standardized patient encounters ke robot-mannequins ke computerized virtual environments. Dengan demikian, bidang simulasi mencakup berbagai interaksi, dari pertemuan antara pasien dan dokter serta pertemuan antara sistem dan lembaga yang lebih besar (Kaji, A.H., Bair, A., Okuda, Y., Kobayashi, L., Khare, R., \& Vozenilek, J. 2008).

Hasil penelitian yang dilakukan oleh Ambarika (2016) menunjukkan hasil bahwa edukasi dan simulasi manajemen bencana sebagai salah satu media terbaik untuk mempersiapkan mahasiswa menjadi relawan bencana karena melalui proses pembelajaran dengan dilakukan edukasi dan simulasi bencana dapat meningkatkan pengetahuan dan keterampilan serta kemampuan mahasiswa menjadi relawan bencana sehingga akan meningkatkan kesiapsiagaan menjadi relawan. Edukasi dan pelatihan bencana diperlukan untuk diterapkan di institusi sehingga semua mahasiswa memiliki kesiapsiagaan untuk menjadi relawan bencana karena bencana bisa datang sewaktu-waktu dan hal itu membutuhkan relawan bencana.

Nurudin dan Widaryati (2015) melaksanakan penelitian dengan judul "Pengaruh Pelatihan Penanggulangan Bencana Gempa Bumi Terhadap Kesiapsiagaan Siswa Kelas VII Di Smp Negeri 1 Imogiri Bantul Yogyakarta" dengan hasil terdapat pengaruh pelatihan tentang penanggulangan bencana gempa bumi terhadap kesiapsiagaan siswa kelas VII di SMP N 1 Imogiri Bantul Yogyakarta tahun 2015. Sehingga 
disimpulkan bahwa simulasi sangat efektif terhadap peningkatan kesiapsiagaan sebagai ukuran dari ranah afektif.

Syuaib (2014) melakukan penelitian dengan judul "Pengaruh Strategi Pembelajaran Simulasi terhadap Bermain Peran dan Sikap Siswa terhadap Pengetahuan dan Kesiapsiagaan tentang Bencana Alam" dengan simpulan ada perbedaan signifikan pengaruh strategi pembelajaran berbeda terhadap hasil belajar kesiapsiagaan tentang bencana alam, dengan siswa yang belajar dengan strategi bermain peran lebih akomodatif daripada pembelajaran simulasi.

Berdasarkan hasil penelitian Jonathan, Karnalim, \& Ayub (2016) disebutkan bahwa algoritma dikembangkan untuk mengatasi hambatan-hambatan dalam belajar.

\section{KESIMPULAN DAN SARAN}

Hasil dari penelitian ini adalah terdapat perbedaan nilai rata-rata kompetensi baik sebelum dan sesudah simulasi tentang manajemen kesiagaan bencana untuk kelompok perlakuan dan kelompok kontrol dan simulasi berbasis algoritma dapat peningkatan peran dan kompetensi manajemen kesiagaan bencana pada perawat komunitas di Kota Surakarta

Saran yang dapat disampaikan adalah Program pelatihan perawat dalam hal manajemen kebencanaan diharapkan menggunakan metode simulasi bagi anggotanya untuk meningkatkan pengetahuan, kepercayaan diri, keterampilan dan kemampuan berfikir kritis.

\section{DAFTAR RUJUKAN}

Ahayalimudin, N.A., Ismail, A. \& Mohd Saiboon, I.M. 2012. Disaster management: a study on knowledge, attitude and practice of emergency nurse and community health nurse. BMC Public Health, 12 (Suppl 2): A3 doi:10.1186/1471-2458-12S2-A3.

Arikunto, S.2010. Metode Penelitian. Jakarta: Rineka Cipta.

Departemen Kesehatan R.I.2008. Keputusan Menteri Kesehatan RI Nomor 406/Menkes/SK/IV/2008 tanggal 25 April 2008 tentang Pebentukan Pemuda Siaga Peduli Bencana (DASIPENA). Tersedia pada: www.depkes.go.id.

Istiqomah.2014. Zonasi Tingkat Kerentanan (Vulnerability) Banjir Daerah Kota Surakarta. Surakarta: Universitas Muhammadiyah Surakarta.

Jonathan, F.C., Karnalim, O., \& Ayub, M. 2016. Extending The Effectiveness of Algorithm Visualization with Performance Comparison through Evaluation-integrated

Development. Proceeding Seminar Nasional Aplikasi Teknologi Informasi (SNATi) 2016 ISSN: 1907 - 5022 Yogyakarta, 6 Agustus 2016

Kaji, A.H., Langford, V., \& Lewis, R.J. 2008. Assessing hospital disaster preparedness: a comparison of an on-site survey, directly observed drill performance, and video analysis of teamwork. Ann Emerg Med. 2008 Sep;52(3):195-201, 201.e1-12.

Kiswiranti, D. dan Brotopuspito, K.S. 2013. Analisis Statistik Temporal Erupsi Gunung Merapi. Jurnal Fisika Vol. 3 No. 1, Halaman 3742. 
Moabi, R.M.2008. Knowledge, Attitudes And Practices Of Health Care Workers Regarding Disaster Preparedness At Johannesburg Hospital In Gauteng Province, South Africa. Johannesburg: University of the Witwatersrand.

Spieler, S.S., Singer, M.P., \& Cummings, L.2008. Emergency Preparedness in Public Hospitals: Complete Findings of the 2006-2007 Emergency Preparedness Study. National Association of Public Hospitals and Health.

Pemerintah Kota Surakarta. (2018). Figur Kota Surakarta tahun 2017. Surakarta: Pemerintah Kota Surakarta.

Peraturan Kepala BNPB Nomer 4 Tahun 2008 Tentang Pedoman Penyusunan Rencana penanggulangan Bencana.

Peraturan Menteri Kesehatan Republik Indonesia Nomor:1949/Menkes/Per/IX/ 2011 Tentang Pedoman Teknis Geladi Penanggulangan Krisis Kesehatan.

Peraturan Pemerintah Nomer 21 Tahun 2008 Tentang Penyelenggaraan Penanggunggulangan Bencana.

Pusat Penanganan Krisis Kesehatan, 2010. Pedoman Gladi Kesiagaan Bencana. Jakarta: PPK Kesehatan Kemenkes RI.

Undang-Undang Nomor 24 Tahun 2007 tentang Penanggulangan Bencana.

Pusat Penelitian Pengembangan Program Pendidikan.1999.

Konsep

Kompetensi. Jakarta: Pusat Penelitian Pengembangan Program Pendidikan.

Spain, K.M., Clements, P.T., DeRanieri, J.T. BCECR, \& Holt, K. 201.
Emergency Preparedness for Nurse Practitioners. Journal for Nurse Practitioners. 2012; 8(1): $38-44$.

Sugiyono.2007. Statistika Untuk Penelitian. Bandung: Alfabeta.

Valdez, C.D., \& Nichols, T.W. 2013. Motivating Healthcare Workers to Work During a Crisis: A Literature Review. Journal of Management Policy and Practice. Vol. 14(4). P.43-51.

WHO. 2008. Nursing Disaster Competencies Handbook. Geneva: $\mathrm{ICN} \& \mathrm{WHO}$. 